\title{
Serum lipid changes following the completed stroke syndrome
}

\author{
F. D. Hollanders* \\ M.Sc., M.B., M.R.C.P.
}

\author{
J. SHAFAR \\ M.D., F.R.C.P., D.P.H.
}

\author{
P. BURTON \\ B.Sc., M.C.B. \\ Department of Medicine, Burnley and District Hospital Group, Lancashire
}

\section{Summary}

Levels of serum cholesterol and M-particle lipoprotein have been monitored in twenty-six patients after the onset of the completed stroke syndrome. Measurements were made regularly over the first 4 weeks and again at 3 months. A steady fall in serum cholesterol was noted which evened out after the ninth day and returned to the original level by the third month. M-particle lipoprotein showed no change in the first 4 weeks but a significant rise over the original level was demonstrated at 3 months.

Some implications of these findings are discussed and it is concluded that, if required, valid serum cholesterol measurements can be made following the completed stroke syndrome provided the blood sample is withdrawn within $24 \mathrm{hr}$ of the acute episode. These findings accord well with those after myocardial infarction.

\section{Introduction}

The existence of a relationship between a raised serum cholesterol level and myocardial infarction is well known (Kagan et al., 1962; Nefzger et al., 1967). A fall in serum cholesterol occurring soon after myocardial infarction is also well documented and has led to the suggestion that serum lipid studies should be delayed until some 2 months after the infarct (Watson, Buchanan and Dickson, 1963). More recent work, however, indicates that a valid cholesterol profile can be obtained provided the blood for analysis is withdrawn within $24 \mathrm{hr}$ of the acute attack (Fyfe et al., 1971; Mundy and McPherson, 1973).

The relationship between serum cholesterol and the completed stroke syndrome is less precise (Greenhouse, 1971) but there is now good evidence to indicate that raised serum cholesterol does predispose to cerebral infarct particularly in those people whose cholesterol level is elevated before they reach 50 years of age (Kannel, 1966). This makes a lipid profile a justifiable investigation in cases of cerebral infarct, especially those of younger age groups.

* Address for reprints: Burnley General Hospital, Medical Records Department, Casterton Avenue, Burnley, Lancashire BB10 2PQ.
The purpose of the present work was to determine whether a fall in serum cholesterol analogous to that following myocardial infarction also occurs after the acute hemiplegic stroke syndrome and, if so, how soon an associated hyperlipidaemic state can be reliably detected after the onset of the acute attack.

\section{Patients and methods}

The patients consisted of a consecutive surviving group of twenty-six examples of the acute hemiplegic stroke syndrome, collected over a 12-month period, of whom fourteen were male and twelve female. Ages ranged from 38 to 69 years with a mean of 60 years. A right hemiparesis was present in seventeen and a left hemiparesis in nine.

The diagnosis of completed stroke syndrome were based on clinical observation supported by radiology of chest and skull, lumbar puncture and routine haematological and biochemical investigation. $\mathrm{Pa}$ tients with blood in the cerebrospinal fluid were excluded.

Venous samples were withdrawn, without recourse to a tourniquet, after a 12-hr overnight fast, the initial sample being taken at 9 a.m. on the morning of the first full day in hospital (designated day 1). In all cases this was within $24 \mathrm{hr}$ of the acute attack. Subsequent samples were obtained at 9 a.m. on days $2,3,4,6,9,12,16,21$ and 28. All patients were followed-up in the Outpatient Department and a further blood sample was examined 3 months after the original event. Serum cholesterol was measured according to the method of Annan and Isherwood (1969) using an auto-analyser and S- and $M$ particle levels were determined by nephelometry according to the method of Stone and Thorpe (1966).

\section{Results}

The results for serum cholesterol measured directly are shown in Fig. 1. Mean cholesterol levels fell rapidly after the acute episode from $259( \pm 10)$ $\mathrm{mg} \%$ to level off by day 9 at $212( \pm 10) \mathrm{mg} \%$; this represents a drop of $18 \%$. The mean serum cholesterol 3 months after the initial episode was found to 


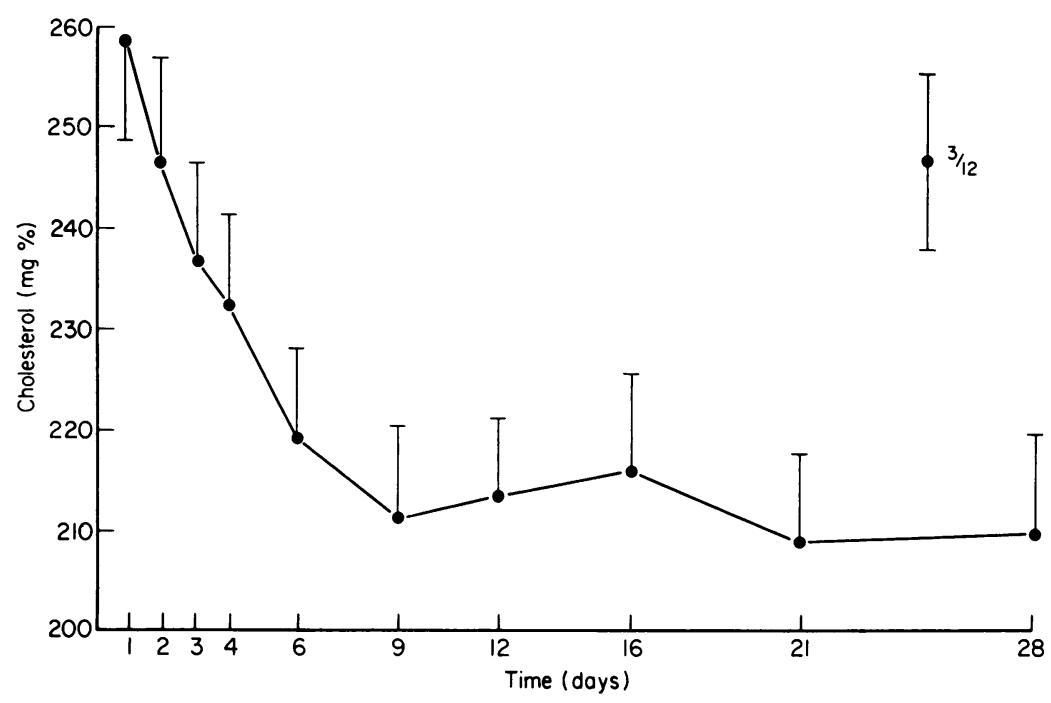

FIG. 1. The fall in serum cholesterol following the completed stroke syndrome. Each point represents the mean cholesterol level from twenty-six patients and is expressed in $\mathrm{mg} / 100 \mathrm{ml}$ of serum together with the standard error.

have risen to $246( \pm 9) \mathrm{mg} \%$. The mean rise from the steady state level between days 9 and 28 to the value at 3 months is very significant $(P<0.01)$ but there is no significant difference between the initial level on day 1 and that 3 months later. These findings are summarized in Table 1.

TABLE 1. Changes in serum cholesterol levels over 3 months in twenty-six patients with completed stroke syndrome. Cholesterol is expressed as $\mathrm{mg} / 100$ $\mathrm{ml}$ of serum + s.e. mean. N.S. = not statistically significant

$\left.\begin{array}{lcc}\hline \multicolumn{1}{c}{\text { Time }} & \begin{array}{c}\text { Cholesterol } \\ (\mathrm{mg} \% \pm \text { s.e. })\end{array} & \text { Difference } \\ \hline \text { Day 1 } & 259( \pm 10) \\ \text { Days 9-28 } & \begin{array}{l}212( \pm 10) \\ \text { 3 months }\end{array} & 246( \pm 9)\end{array}\right\} \begin{gathered}34 \mathrm{mg}( \pm 13) \\ (P>0.01)\end{gathered}$

Difference day 1 and 3 months $=$ N.S.

The S-(small) particle fraction of the serum lipids was measured by the nephelometer and the pattern of its variation with time corresponds very closely to that for cholesterol. This is presented graphically in Fig. 2 without further comment.

M-particle levels were also obtained by nephelometry and the results are presented as an M-particle score in Table 2. No significant change occurred in the first 28 days, the mean value throughout this period being $3 \cdot 1( \pm 0 \cdot 4)$. At 3 months, however, the score had risen to $3.9( \pm 0.4)$, an increase which just reaches statistical significance $(P<0.05)$.
No correlation could be demonstrated between either the rate of decline or the steady state cholesterol levels and the severity of the hemiplegia.

The weights of the patients were recorded on admission and thereafter at weekly intervals. In the initial 9-day period during which serum cholesterol levels fell there was no significant change observed in the weight of each case although ultimately body weights did tend to increase slightly, especially in those cases requiring prolonged admission.

\section{Discussion}

A progressive fall in serum cholesterol level following the completed stroke syndrome has been demonstrated, with a return to initial levels 3 months later. It is recognized that similar reductions in cholesterol levels occur following myocardial infarction (Fyfe et al., 1971; Mundy and McPherson, 1973), after severe pain (Keele and Stern, 1973), post-operatively (Man et al., 1946) and during infection (Groen et al., 1952). The factors responsible for these changes are still obscure but Keele and Stern (1973) and Mundy and McPherson (1973) have attributed them directly to pain and myocardial infarction respectively. As regards pain no patient involved in the present study complained specifically of this symptom at any time.

It has been suggested that increased catecholamine secretion after a myocardial infarction may be implicated in the serum lipid alterations observed in that condition (Tibblin and Cramer, 1963). Serum cortisol levels were monitored in the present series of patients 


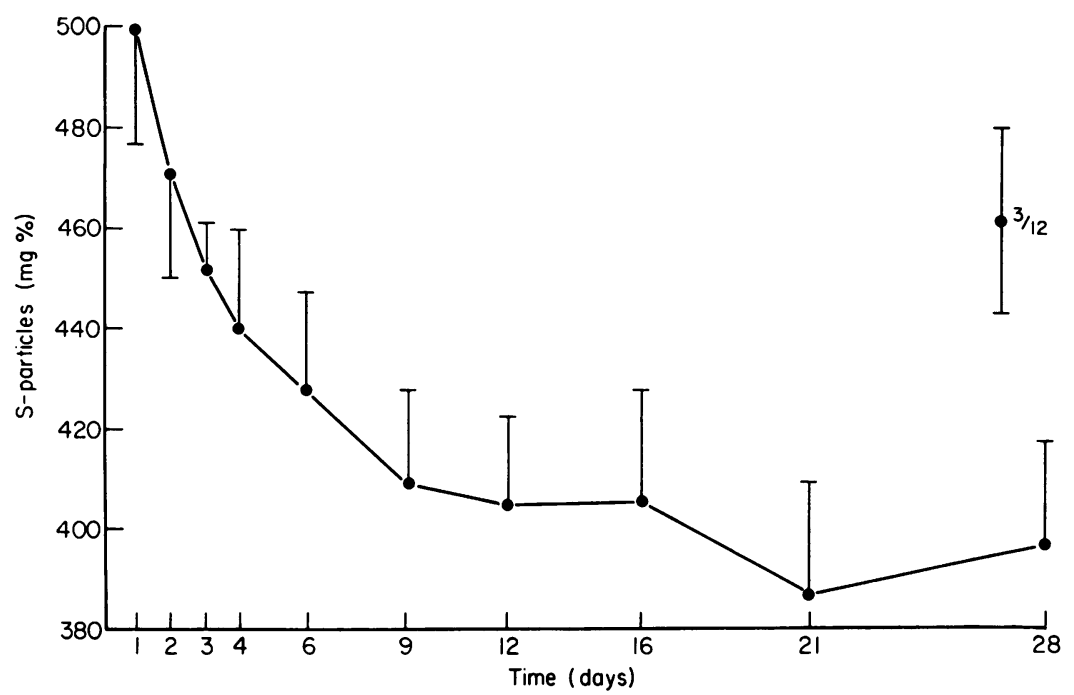

Fig. 2. The fall in serum cholesterol following the completed stroke syndrome as measured by nephelometry. The cholesterol is represented by the $\mathbf{S}$ (small)-particle fraction and is expressed in $\mathrm{mg} / 100 \mathrm{ml}$ of serum together with the s.e. mean. Number of cases $=$ twenty-six.

TABle 2. Serum M-particle lipoprotein levels measured by nephelometry in twenty-six cases of completed stroke syndrome. Results are expressed as an $\mathbf{M}$ (medium)-particle score plus standard error according to the recommendation of Stone and Thorpe (1966). A statistically significant difference exists between the level on day 1 and that 3 months later $(P<0.05)$ but no significant difference can be demonstrated over days 1-28

\begin{tabular}{cc}
\hline $\begin{array}{c}\text { Days after } \\
\text { onset }\end{array}$ & $\begin{array}{c}\text { M-particle } \\
\text { (score } \pm \text { s.e.) }\end{array}$ \\
\hline 1 & $3.2 \pm 0.3$ \\
2 & $3.0 \pm 0.3$ \\
3 & $3.2 \pm 0.4$ \\
4 & $3.2 \pm 0.4$ \\
6 & $2.9 \pm 0.3$ \\
9 & $2.9 \pm 0.3$ \\
12 & $2.9 \pm 0.3$ \\
16 & $3.3 \pm 0.3$ \\
21 & $3.4 \pm 0.5$ \\
28 & $3.2 \pm 0.7$ \\
3 months & $3.9 \pm 0.4$ \\
\hline
\end{tabular}

(to be published) and showed that initially cortisol levels were raised and the diurnal variation annulled, but by the second to third day after the acute episode the levels had re-established themselves within the accepted range of normal as had the diurnal variation. Serum cholesterol values, however, in these same patients continued to fall in an almost linear fashion until the ninth day.

Seasonal change in serum cholesterol (Fyfe et al.,
1968 ) is also thought unlikely to be of major importance. The patients presented at a reasonably steady rate over a period of 12 months. Those admitted when seasonal variation was in a downward direction (six) would be roughly balanced by those admitted when the variation was in an upward direction (eight). The remainder entered the study at a time when cholesterol would be expected to be steady.

Other factors known to affect serum cholesterol levels such as posture (Tan et al., 1973), the use of a tourniquet in blood sampling (Koerselman, Lewis and Pilkington, 1961) and spontaneous daily variation (Cromie et al., 1963) are not considered to be important in the genesis of the cholesterol pattern presently reported. In view of the divergent nature of conditions attended by a fall in serum cholesterolmyocardial infarct, severe pain, infection and, now, the completed stroke syndrome-the possibility arises that the fall depends not so much on the nature of the pathology but more on such non-specific factors as are involved in removing a patient to the hospital environment with the inevitable psychological stress, change in diet, alteration in level of activity, etc. More work is required to elucidate the relative importance of such influences.

The results do, however, prompt comment on the work of previous investigators whose aim was to study the relationship between cholesterol and the completed stroke syndrome. Many such studies rely on a single blood determination of cholesterol and this is compared with that of a control group. For 
instance, Robinson, Higano and Cohen (1963) withdrew blood 4 weeks after the acute stroke which, according to the present results, would yield a cholesterol level about $18 \%$ below the pre-infarction level. These considerations may go some way to explaining the discrepancy found in the literature regarding the existence of a relationship between serum cholesterol and the stroke syndrome.

That some workers do find a positive correlation between cholesterol and stroke is well known, this being strongest in those afflicted before the age of 50 years (Kannel, 1966). In these patients, therefore, determination of serum cholesterol would be of importance and the present work indicates that provided the sample is taken within $24 \mathrm{hr}$ of the acute attack the value obtained is not significantly different from that of 3 months later and, by inference, is likely to present a good guide to the pre-infarction cholesterol level. This finding corresponds closely to that reported after myocardial infarction (Fyfe et al., 1971; Mundy and McPherson, 1973).

The changes in M-particle lipoprotein after completed stroke syndrome as scored by the nephelometer do not appear to have been described previously and are presented in Table 2. Levels fluctuated throughout the first 28 days and no statistically significant change could be demonstrated. At 3 months after the acute episode, however, M-particle lipoprotein had risen significantly above the mean value for the first 28 days. Many authorities accept that M-particle lipoprotein, as measured by nephelometry, correlates well with levels of serum triglyceride measured chemically (Dean, 1974). Our results could, therefore, be interpreted as representing a trend towards increasing serum triglyceride levels over the weeks following the completed stroke syndrome. A similar trend has previously been reported by Katsuki et al. (1964).

In concluding, we suggest that valid cholesterol levels can be determined on the morning after the onset of the completed stroke syndrome and that lipid profiles taken at this time, particularly in the younger patient, will provide a satisfactory screening procedure and allow the earlier institution of treatment directed to the lowering of a raised serum cholesterol.

\section{Acknowledgments}

The authors wish to express their sincere thanks to $\mathrm{Mr} \mathrm{K}$. Cottrell, Statistician to the North Western Regional Health Authority, Manchester, for statistical help and to Mrs Gloria Lord for her willingness and ability in typing the manuscript.

\section{References}

ANNAN, I.W \& ISHERWOOD, D.M. (1969) An automated method for the direct determination of total serum cholesterol. Journal of Medical Laboratory Technology, 2, 202.
Cromie, J.B., Thomson, M.J., Cullimore, O.S. \& BeACH, E.F. (1963) Studies in serum lipids with special reference to spontaneous variations and the effect of short term dietary changes. Circulation, 27, 360.

DEAN, F.D. (1974) Comparison of the micronephelometric and enzymatic methods for the determination of serum triglycerides. Clinica chimica acta, 50, 367.

Fyfe, T., BaXTer, R.H., Cochran, K.M. \& Booth, E.M. (1971) Plasma lipid changes after myocardial infarction. Lancet, ii, 997.

Fyfe, T., Dunnigan, M.G., Hamilton, E. \& RaE, R.J. (1968) Seasonal variations in serum lipids and incidence and mortality of ischaemic heart disease. Journal of Atherosclerosis Research, 8, 591.

GreENHOUSE, A.H. (1971) Blood lipids and strokes: Are they related? Journal of Chronic Diseases, 23, 823.

Groen, J., Turong, B.K., Kamminga, Chr.E. \& WilleBRANDS, A.F. (1952) The influence of nutrition, individuality and some other factors, including various forms of stress, on the serum cholesterol: An experiment of nine months duration in 60 normal human volunteers. Voeding, Den Haag, 13, 556.

Kagan, A., DaWber, T.R., KanNell, W.B. \& ReVotskie, N. (1962) The Framingham Study: A prospective study of coronary heart disease. Federation Proceedings, 21, 52.

KANNEL, W.B. (1966) In: Cerebral Vascular Diseases (Ed. by C. H. Millikan), p. 53. Grune and Stratton, New York.

Katsuki, S., Uzawa, H., Fujimi, S., Shiratsuchi, K. \& Ito, Y. (1964) Studies on blood lipids in cases with cerebrovascular disease. Japanese Heart Journal, 5, 101.

Keele, K.D. \& Stern, P.R.S. (1973) Serum lipid changes in relation to pain. Journal of the Royal College of Physicians of London, 7, 319.

Koerselman, H.B., Lewis, B. \& Pilkington, T.R.E. (1961) The effect of venous occlusion on the level of serum cholesterol. Journal of Atherosclerosis Research, 1, 85.

Man, E.B., Bettcher, P.G., Cameron, C.M. \& Peters, J.P. (1946) Plasma X-amino acid nitrogen and serum lipids of surgical patients. Journal of Clinical Investigation, 25, 701.

Mundy, G.R. \& McPherson, D.G. (1973) Variations in serum cholesterol levels after myocardial infarction. Medical Journal of Australia, 1, 278.

Nefzger, M.D., Heyman, A., LeBauer, J., Friedberg, S. \& LEWIS, J. (1967) Serum cholesterol levels in myocardial and cerebral infarction caused by atherosclerosis. Journal of Chronic Diseases, 20, 593.

Robinson, R.W., Higano, N. \& Cohen, W.D. (1963) Comparison of serum lipid levels in patients with cerebral thrombosis and in normal subjects. Annals of Internal Medicine, 59, 180.

Stone, M.C. \& ThORPE, J.M. (1966) A new technique for the investigation of the low density lipoproteins in health and disease. Clinica chimica acta, 14, 812.

Tan, M.H., Wilmshurst, E.G., Gleason, R.E. \& Soeldner, J.S. (1973) Effect of posture on serum lipids. New England Journal of Medicine, 289, 416.

Tibblin, G. \& Cramer, K. (1963) Serum lipid levels during the course of an acute myocardial infarction and one year afterwards. Acta medica scandinavica, 174, 451.

Watson, W.C., Buchanan, K.D. \& Dickson, C. (1963) Serum cholesterol-levels after myocardial infarction. British Medical Journal, ii, 709. 